\title{
Participant Observation of a Mars Surface Habitat Mission Simulation
}

\author{
William J. Clancey \\ NASA-Ames Research Center \\ Computational Sciences Division MS269-3 \\ Moffett Field, CA 94035 \\ and \\ Institute for Human and Machine Cognition \\ University of West Florida, Pensacola \\ bclancey@arc.nasa.gov
}

\begin{abstract}
For twelve days in April 2002 we performed a closed simulation in the Mars Desert Research Station in Utah, isolated from other people, while exploring the area and sharing daily chores. Email provided our only means of contact; all mission-related messages were mediated by a remote mission support team. This protocol enabled a systematic and controlled study of crew activities, scheduling, and use of space. The study was primarily a methodological experiment in participant observation and work practice analysis, gathering quantitative data as part of an ethnographic study. The work practice analysis focused on two questions: Where did the time go-why did the crew feel rushed and unable to complete their work? How can we measure productivity, to compare habitat designs, schedules, roles, and tools? Analysis suggests that a simple scheduling change-having lunch and dinner earlier, plus eliminating afternoon meetings - increased the available productive time by $41 \%$. Furthermore, observation of work practices suggested how to eliminate direct use of GPS devices by the crew, illustrating how an ethnographic study can help produce dramatically new operations concepts.
\end{abstract}

\section{INTRODUCTION}

Total time-over an hour-and this is pretty typical of where we are right now with stowage. This will definitely get better soon, but planners need to bear with us with all the mysterious "overhead."

International Space Station ship log, November 22, 2000

The Mars Desert Research Station (MDRS) is an analog to a Mars surface habitat, constructed for mission simulations according to Mars Reference Mission guidelines (Hoffman \& Kaplan 1997), and located in a US southwest desert region relevant to Mars analog geology and biology research. MDRS includes an upper deck with six private staterooms having personal storage and desks, a galley area, workstations, and meeting/eating area, plus a lower deck with a laboratory, toilet, shower, and extra-vehicular activity (EVA) preparation rooms. This facility is similar to the Flashline Mars Arctic Research Station (Clancey, 2000b, 2001b), part of a series of research stations designed and built by the Mars Society (Zubrin 2003), to include alternative designs in Iceland and Australia.

Almost 200 people have occupied MDRS over three field seasons, usually in two-week rotations with crews of six people. The fifth crew (MDRS5) occupied the hab in April 2002, in a simulation that was closed - no visitors or conversations with outsiders, including telephone - for 12 days. The members of the crew included a biologist, geologist, geophysicist, aerospace engineer, and journalist, as well as the author, a computer/cognitive scientist, who organized the simulation and served as commander. As has 
been common practice, the crew's identity and daily reports were public, posted on the Mars Society web site.

The study reported here was an exploratory methodology experiment, using the methods of participant observation (Spradley 1980; Johnson \& Sackett 1998), which in this context means that a crew member conducts the study, and work practice analysis (Luff et al. 2000), involving gathering data to understand how people actually use their time and solve problems. The study's focus is not so much on specific hypotheses about crew skills, team interactions, habitat layout, scheduling, etc., but about what different methods - for observing, recording, describing, and analyzing an analog mission in a surface habitatreveal about operations and habitat design. Methodological questions include:

1) Applying time lapse to the entire mission, what can be learned? Can analysis be partly automated?

2) Applying ethnography to a closed simulation: Can a fulltime participant (the commander) carry out ethnographic observation? What are the opportunities and limitations? How should the study interpret different types of public and private documents?

3) Closed simulation: Is it possible to use MDRS in closed simulation mode, while satisfying needs for safety, maintenance, resupply, and outreach?

4) Beyond time lapse, what photographic or other observational records are available for systematic observation?

5) What space human factors questions might be studied in a closed simulation involving authentic science EVAs at MDRS?

a) How can we relate human factors and industrial engineering more broadly to the concerns and methods of work system design?

b) What is the relation of space mission work system design issues to office-based workplace studies?

Within this context, the study was oriented to several questions that had emerged on previous simulations (Clancey 1999; 2000a,b; 2001a) as being relevant to planning long-duration missions in remote settings. These questions influenced what data was systematically gathered during the study, as well as the chosen protocol for the simulation:

- What is the effect of chores (e.g., life support maintenance) on science productivity?

- How do plans develop and change during the mission?

- How do individual and group activities interact during the day?

- How can Earth's mission support understand and assist Mars surface exploration? Can possible EVA targets and routes be suggested using reports from previous crews?

- How is public and private space used? How can the habitat's layout be improved?

At the same time, four crew members were conducting their own investigations:

- If there is life on Mars, how do you take a soil or rock sample that includes it?

- Can a geologist understand the work performed by previous rotations to develop a geology primer of the region?

- What are the psychological effects of growing plants in the hab?

- What kinds of journalistic stories best chronicle the crew's experience? 
To appreciate the perspective of the MDRS5 ethnographic study, I review and synthesize related work, placing work practice observation in the context of industrial engineering and space human factors research. The present study may be viewed as a natural evolution that adapts business design methods from everyday workplaces to space facilities and operations engineering. Just as industrial engineering and psychology moved engineering from survivability to design for comfort and task performance, the methods and insights of business anthropology may be viewed as another step in advancing how engineering design considers the needs and interests of the crew. In using work practice observational and analytic techniques (Clancey, in preparation), we begin to consider how facilities, roles, tools, systems, etc. interact in practice. For example, how tools are used in practice sometimes contradicts locally optimized designs, automation may generate new burdens for maintenance and control (Zuboff 1988).

To begin, a general background is presented, relating participant observation of work practices to other kinds of people-oriented studies. Next, related work is briefly surveyed to clarify the nature of previous studies and to place MDRS in the context of missions and space analog habitats. Finally, as part of this introduction, the MDRS5 simulation is more formally described by dimensions recommended for formalizing mission operations in "trade studies."

Subsequent sections then describe data collection and analysis techniques, discuss results, and make conclusions about future work.

\section{BACKGROUND: PARTICIPANT OBSERVATION OF WORK PRACTICES}

Conventionally, space human factors considers especially the roles of the crew members, relative to human physical and mental capabilities, requirements for life support/space/training, etc., and alternate operations concepts (Woolford \& Bond 1999, p. 135). A multidisciplinary endeavor, with concerns ranging from perception to organizational dynamics, the field has been shaped by the methods of psychology, emphasizing focused studies, functional (task performance) based design (including function allocation, procedures, automation, and training), and the use of tests and surveys for evaluating psychological states, capabilities, and experience (Connors, Harrison, and Akins 1985).

As a typical example, Cohen's (1997) architectural design guidelines for Sofia, an airborne observatory, considers how layout of human interactions and equipment access during operations affect productivity, comfort. and safety. In the same vein, regular post-mission debriefings of International Space Station (ISS) crew members are conducted by NASA human factors researchers to investigate "operational habitability." These are confidential, often short interviews that focus on aspects of the mission, environment, or hardware that could be modified to increase the crew's living and working experience, especially to reduce problems and improve work efficiency. Questions focus on architecture, crew interfaces (e.g., labels, displays, restraints), environment (e.g., acoustics, ventilation, lighting), and operations (e.g., schedule, communications).

The history and nature of space vehicle engineering necessarily places a primacy on issues of life support and safety, followed by issues of comfort and task support. Considering the experience in designing Skylab (Compton \& Benson, 1983) and Mir operations (e.g., Burrough 1998), we can identify several levels of concern in relating the design of a habitat facility to operations:

1. Survivability: Engineers are necessarily first concerned about physiological requirements of keeping the astronauts alive, with strong weight and cost constraints.

2. Comfort: The first contributions by human factors (industrial engineers) is to move beyond safety to improve comfort, with issues ranging from personal hygiene, privacy, and convenient "anthropometric" tools and designs (e.g., foot restraints).

3. Performance: The next level of human factors concerns task support or productivity, relating crew size, skills, tools, automation, procedure manuals, scheduling, training, computer interfaces, 
facilities layout, etc. These considerations may be matrixed against physiological constraints such as fatigue and affects of microgravity. More broadly, industrial engineering observes and analyzes processes systemically to reduce cost and increase productivity.

4. Adaptability: Next, contributions by social scientists focus on crew teamwork, project collaboration (e.g., with scientists on earth), creative workarounds, informal assistance, replanning, and learning during the mission.

The history of work in space somewhat parallels the development of business analysis and design techniques in factories and offices. By the late 1960s (when Skylab was designed), engineers were working with industrial designers; by the mid and late 1970s, psychologists were bringing cognitive task analysis to the workplaces; and by the late 1980s, anthropologists and sociologists were focusing on work practice (the circumstantial factors of how people actually got their jobs done). All of the disciplines and methods have a common interest in people (as indeed, even the Gilbreths' original time-and-motion studies were viewed as "applying the social sciences...emphasizing the worker rather than nonhuman factors" [Britannica 1987]). Today most specialists appear to have an increasing appreciation of the contextual, interactive nature of human experience and the dynamic character of work, systems, and the environment. The levels do not imply the evolution of a method or supplanting of disciplines, rather specialists increasingly work together. As design considerations become more complex, the work becomes more multidisciplinary.

Human factors specialists, including psychologists and engineers, are concerned with moving mission engineering from survivability to consider comfort and performance. Today's workplace studies (Luff et al. 2001) are dominated by social scientists, especially anthropologists, seeking to move the discourse beyond task analysis to understand and support work practices as inherently social-concerning participation (belonging/role), relationship (based on friendship and personal history), and learning (including information sharing, friendly assistance, and promoting the community). At this point, what workplace researchers call "the system of work" is understood to extend well beyond the frame of the habitat, to include the scientists with a vested interest in the mission, how the support team is managed and communicates among themselves, and public stakeholders.

The four "levels" summarized here may be fruitfully viewed as interacting perspectives, with a compositional effect, loosely resembling Maslow's Hierarchy of Needs (physiological, safety, love, esteem, self-actualization). Each level requires a degree of flexibility that broadens those below. For example, a certain architectural design may ensure survivability, but be extremely uncomfortable (e.g., the Soyuz capsule). A comfortable module may be extremely inconvenient for getting work done (e.g., the original location of network ports in ISS). A procedure or tool "optimized" for a task may inhibit open communication or receiving help when needed from a crewmate.

Indeed, as MDRS5 experience showed, the problem with a software program, for example a geographic information system (GIS), might not just be that its interface is difficult to use (which is obvious enough), but that the crew is forced to communicate in terms of location coordinates at all. Reducing human factors to "interface design" - a prevalent way anthropologists are greeted by engineers familiar with human factors research - threatens to not see the forest for the trees. A total systems perspective is required, sometimes radically transforming operations concepts, before becoming concerned with localized optimizations such as screen design or tool anthropometrics.

Within the workplace studies community (e.g., Bannon 1991; Luff et al. 2000) arguments have been made that systems cannot be designed successfully from the bottom up; subsystems do not compose linearly and predictably. Rather, technologies and methods developed for life support, personal hygiene, and work tasks (to give typical concerns of each level) must be re-evaluated in the context of practical scenarios that include especially unexpected maintenance, interruptions, rework (e.g., because an instrument was used incorrectly or failed to function properly), feedback of results to scientists for 
replanning, adjusting schedules during the course of the mission (e.g., for variety, opportunity, revised goals).

Crucially, a holistic perspective emphasizes that properties (e.g., "human capability") do not exist in isolation, but are relational, depending on context, which is always physical and interpersonal, as well as historical, involving both experience and expectation. Thus predicting what people can actually accomplish during a spaceflight, including their limitations and strengths, needs to be somehow triangulated from laboratory and workplace studies, similar space missions (e.g., relating Apollo to Mars), and mission simulations.

As we move from the laboratory to analog missions on earth to, for example, space station simulations of Earth-to-Mars transit, we will discover what combinations of facilities, roles, tools, etc. work in practice and gain increasing confidence about the right design for an actual mission. However, our theoretical stance tells us that even then we will have a lot to learn, and should design habitats and all aspects of the mission for adaptation during the mission.

The study reported here may be viewed as an experiment in bringing ethnographic methods to the realm of crewed spaceflight. The novel contribution is not so much the consideration of "social" or "organizational" factors, which of course appear in psychological studies of crew interactions (e.g., Kanas 2002), but rather the methods of participant observation (the researcher is a member of the crew) and work practice analysis (a close study of circumstantial interactions of facilities, behaviors, systems, communications, documents, etc.).

In summary, to understand the present study's methods and objectives, one must consider the methodological context in which it arose. This background includes the application of ethnography to business settings for work system design (Greenbaum \& Kyng 1991; Blomberg et al. 1993; Jordan 1994; Burton \& Harper 1996), and the introduction of empirical requirements analysis to software engineering (Floyd 1987; Ehn 1988; Beyer \& Holtzblatt 1998). In this work, social scientists reacted critically to workplace automation that resulted from too narrow, functionally-based interpretations of "human factors" (e.g., Zuboff 1988; Bradley 1989; Bannon 1991). Against this background, investigating the opportunities for computer tools in Mars surface missions, the author has conducted an ethnographic study of field science and expeditions over six years. This experience includes participant observation in four Haughton-Mars expeditions from 1998-2003 (Clancey 1999, 2000a, 2001a), plus being a crew member of a simulated mission in the Flashline Mars Arctic Research station for two weeks (Clancey, 2001b). As part of this ongoing ethnographic study, the MDRS5 simulation was designed to provide more useful, quantitative data by controlling the crew's interactions with outsiders and systematically using video, logging, and surveys-while looking for ways to use computer technology that would greatly improve the crew's productivity.

\section{RELATED SPACE HABITAT RESEARCH}

Here I place the MDRS5 mission simulation in the context of other experiments and analyses that involve crews living and working in a space module or surface analog habitat.

Stuster's Bold Endeavors (1996) reviews "lessons from polar and space exploration" organized around factors (e.g., leadership) affecting the nature of human experience in isolation, particularly when carrying out dangerous or stressful endeavors in "naturally occurring groups." Stuster used interviews, logs and journals, debriefing reports, and historical accounts (p. 22). Similar to the present study, he focuses on how people succeed in living and working under adverse conditions (p. 33), instead of focusing on disasters, dysfunctions, and limitations (e.g., fatigue, stress). Thus, he tends to views expeditions holistically, in terms of the crew's adaptation through their interactions. This perspective gives somewhat more weight to social issues, and views psychological factors in that context. Thus, Stuster's analysis 
moves beyond task analysis to understand adaptability, including motivation, in terms of social relationships.

The Lunar-Mars Life Support Test Project (LMLSTP, aka "JSC chamber studies") involved a mission simulation with a crew of four living in a closed chamber for four experimental periods of 15 days and one through three months. The objective was to "validate regenerative life support technologies"-all air and water was recycled (often called CELSS for controlled or closed ecological life support systems). These simulations are highly complementary to the present MDRS study. They focused on logistics (design for survivability and comfort), rather than exploration work (e.g., EVAs and reporting). Human factors studies included remote training methods, habitability, and mental self-health monitoring. Researchers did not seek to record or analyze activities ("a day in the life of the chamber"), workflow, or how interactions between people, facilities, tools, procedures, protocols, etc. influenced learning and creative problem solving. All of the methods used for MDRS5 might have been applied in the JSC chamber to study work practice.

Showing the dramatic differences in perspective, one might say that LMLSTP focused on life support loops, while MDRS5 (and later work such as MDRS29; Clancey et al. 2004c, Sklar 2004) focused on communication system loops (e.g., collaboration with PIs and other remote scientists, access of data to earth support and science teams, collaborative planning tools, automated database creation and notification of information). The example shows when we use the term "integrated system" we must be clear about where we draw boundaries to define the system. In contrast with JSC chamber studies, MDRS research is concerned with exploration systems - thus gaining a broader picture of the stakeholders and constraints, but losing some fidelity because the MDRS5 life support subsystem was ad hoc.

Shuttle/Mir space station missions and Mir simulations (conducted with a three-person crew over four months or more in Moscow) were studied by Kanas and his colleagues, focusing on psychosocial aspects of isolation in small crews. The data consists of confidential weekly questionnaires (standardized psychometric instruments, e.g., profile of mood states), plus subjects" "critical incident log" of important events of the preceding week (Kanas 2002, p. 308). Understanding psychosocial influences on communications between the crew and mission support is highly relevant to work practice analysis.

Aquarius is an undersea habitat anchored off Key Largo. The NASA Extreme Environment Mission Operations Project (NEEMO; Todd \& Reagan 2004) has used Aquarius for dozens of astronaut mission training missions (e.g., to practice team skills). The combination of authentic work doing space analog science, dangerous remote environment, and space-like nature of EVA dives makes Aquarius a unique space analog research station.

NEEMO's two-week missions and EVA simulations parallel the experience at MDRS, but the objectives and design philosophies are quite different. For example, a detailed timeline is planned by mission control in Houston for each crewmember's day, including specific timeslots for each activity, including outreach, sleep, chores, hygiene (Todd and Reagan 2004, p. 755). In contrast, seeking to experiment with alternative operations concepts, the MDRS5 crew replanned its activities on a daily basis at the crew's briefing meeting. NEEMO missions have not included formal reports of EVAs or science activities, a crucial part of exploration, and significant use of crew time. NEEMO has permitted real-time interactions with NASA "topside" during briefings and EVAs, thus paralleling near-earth orbit or lunar missions, rather than experimenting with time-delayed communications.

Because of the training objective, rather than exploration research, the NEEMO project attempts to mimic the space experience (e.g., types of food and "look" of the procedures), than to simulate a radically different mission: "The fact that there were mission rules, prioritized objectives, and procedures made for a strong comparison to space flight" (Todd and Reagan 2004, p. 758). The source of these rules, objectives, and procedures is an open question for long-duration space flight. Furthermore, until recently the NEEMO daily schedule did not include the two onboard support personnel, or consider them to be part of the crew, again because of the focus on training the astronauts, rather than using the habitat to 
conduct holistic simulations. This example underscores that the purpose for using a habitat must be understood before comparing simulation protocols and study methods.

Skylab flights in the 1970s are among the most well-known mission experiments. Skylab is of special interest for Mars preparation for many reasons: configuration of the single-module habitat, emphasizing both laboratory facilities ("workshop") and daily living needs; problems of frank communication between the crew and flight controllers; focus on scientific tasks; food and waste management; EVA repairs; range and nature of mistakes; rigid, over-scheduling by Mission Control.

Although industrial design consultants were able to improve Skylab's layout, lighting, and other matters of "habitability" (Compton \& Benson 1983, Chapter 7), one of most important lessons is that operations had been poorly anticipated and designed. Training and simulations-including the experience of the first two Skylab missions - did not adequately convey to flight controllers how living and working in space needed to be scheduled and coordinated. The commander of the 84-day third mission said, "Obviously [they] were not thinking, they were just coloring squares and filling in checklists. That is no way to operate a mission" (Chapter 17, "Carr Calls for an Assessment").

Strikingly, a decade later, plans for the space station still misconstrued how people would actually spend time in space. For example, studies predicted that making "immediate modifications and repairs" would rank seventh, after "supervising machines" and "conducting on-board experiments," and stated "the station ideally will fly itself" (premises from Space Station Task Force cited by Cohen 1985, p. 4). This typical idealization of what automation can accomplish contrasts with ISS realities (e.g., see the Introduction opening quotation, regarding the time to collect materials for a task).

The primary focus of the ethnographic study of MDRS5 was to understand where all the time goes - why do crewmembers feel that they are not as productive as they should be? Is 25 man-hours of work per day for a crew of three, as found on Skylab-3, a practical limit for long-duration missions? How should this time be scheduled and replanned? How should the day be allocated between personal and group activities? What adjustments can be made to alleviate repetitive attention-demanding tasks, such as scientific reporting? And considering another Skylab lesson, how should progress and problems be communicated with mission support and the public? Perhaps most importantly, what work practice recording and analysis techniques can be brought to bear during a mission, to help the crew reflect on their own situation?

\section{MDRS5 SIMULATION MISSION OPTIONS}

As indicated in describing NEEMO, to understand an analog habitat experiment we must begin with its purpose and assumptions. In the formal design of space missions, a selection among mission options is called a system trade (Larson \& Balogh 1999, p. 29; Connolly 1999). The design of the MDRS simulation was not the result of a trade study, but nevertheless it may be helpful to describe the choices made using a mission options framework. This description might suggest later studies (especially at MDRS or FMARS on Devon Island) and facilitate comparison. The alternatives (second column) reveal both the similarities and great differences in comparing the MDRS5 configuration to a Mars mission.

Table 1 summarizes the choices in selecting the MDRS5 crew and organizing the simulation. The table makes explicit dimensions of mission design and choices that are often implicit, sometimes because they are inherited contextually (e.g., by being a rotation in a series using the same habitat).

Table 1. MDRS5 Mars Mission Options (cf. Table 2-3, Larson \& Balogh 1999)

\begin{tabular}{|l|l|l|}
\hline \multicolumn{1}{|c|}{ Mission Option Area } & \multicolumn{1}{|c|}{ MDRS5 Choice } & $\begin{array}{c}\text { Common alternative(s) } \\
\text { considered for Mars mission }\end{array}$ \\
\hline Crew location & Southwest Utah desert, & In Mars orbit or Phoebes \\
\hline
\end{tabular}




\begin{tabular}{|c|c|c|}
\hline & $\begin{array}{l}\text { simulating habitat on surface of } \\
\text { Mars }\end{array}$ & \\
\hline $\begin{array}{l}\text { Number of crew } \\
\text { members }\end{array}$ & Six & Four \\
\hline Crew gender & Four men, two women & All men; one woman; 50-50 \\
\hline Crew structure & $\begin{array}{l}\text { Commander (Cognitive } \\
\text { Scientist); Health \& Safety } \\
\text { Officer (also Chief Engineer); } \\
\text { Science specialists (Biologist, } \\
\text { Geologist, Geophysicist); } \\
\text { Journalist }\end{array}$ & $\begin{array}{l}\text { Include a pilot, MD, and } \\
\text { aerospace engineer }\end{array}$ \\
\hline $\begin{array}{l}\text { Type of } \\
\text { accommodations }\end{array}$ & Staterooms with work areas & Minimal sleeping area \\
\hline Duration & Two weeks & One month or more \\
\hline $\begin{array}{l}\text { International } \\
\text { participation }\end{array}$ & $\begin{array}{l}2 \text { out of } 6 \text { crewmembers non-US } \\
\text { citizens }\end{array}$ & All American \\
\hline Life support system & Open-loop & $\begin{array}{l}\text { Recycling gray water; } \\
\text { Closed loop }\end{array}$ \\
\hline $\begin{array}{l}\text { In-situ resource } \\
\text { utilization }\end{array}$ & Greenhouse & Extract $\mathrm{H} 2 \& \mathrm{O} 2$ from ice \\
\hline Maintenance & $\begin{array}{l}\text { Crew maintains power, electric, } \\
\text { human waste }\end{array}$ & Selected redundancy \\
\hline $\begin{array}{l}\text { Tasking, scheduling \& } \\
\text { control }\end{array}$ & $\begin{array}{l}\text { Crew does all planning; mission } \\
\text { support provides logistics } \\
\text { assistance; schedule activity } \\
\text { periods, not individual tasks; } \\
\text { chores \& sleep time open to } \\
\text { individuals }\end{array}$ & $\begin{array}{l}\text { Remote team dictates daily } \\
\text { plans, with individual tasks } \\
\text { and personal activities (e.g., } \\
\text { sleep time) on detailed } \\
\text { timeline }\end{array}$ \\
\hline Communications & $\begin{array}{l}\text { Daily commander, engineering, } \\
\text { and health/safety reports; } \\
\text { Detailed EVA reports; Weekly } \\
\text { science reports. Posted with } \\
\text { photos on public web site. }\end{array}$ & $\begin{array}{l}\text { Reports written by mission } \\
\text { support team, including } \\
\text { decisions of what to present on } \\
\text { public web site. }\end{array}$ \\
\hline Mission timeline & $\begin{array}{l}\text { General planning in month } \\
\text { preceding; crew did not meet } \\
\text { prior; crew member replaced in } \\
\text { final two weeks }\end{array}$ & $\begin{array}{l}\text { One year of prior training and } \\
\text { working together }\end{array}$ \\
\hline Crew safety & $\begin{array}{l}\text { Focus on fire and medical } \\
\text { emergencies; flight surgeon on } \\
\text { call }\end{array}$ & $\begin{array}{l}\text { Focus on environmental } \\
\text { dangers (e.g., radiation) }\end{array}$ \\
\hline Habitat Construction & $\begin{array}{l}\text { Prefab panels assembled on site, } \\
\text { ready for crew occupation }\end{array}$ & Modules assembled by crew \\
\hline
\end{tabular}




\begin{tabular}{|l|l|l|}
\hline Design life of habitat & 10 years & 2 years or multiple missions. \\
\hline
\end{tabular}

Of course, several key system trades for a Mars mission are not relevant to our situation, such as the launch and transportation systems.

What is the value of a study of practices relative to system trades? Perhaps most importantly, observing and analyzing how people actually behave - especially when they are given the freedom to discover their own preferences as a team-helps us to identify alternatives that we might not have considered. In this respect, we deliberately chose alternatives for MDRS5 at odds with the usual way of carrying out LEO missions, such as allowing the crew to replan its activities as necessary. In subsequent MDRS experiments, crews have had a remote science team available, allowing experimentation with giving crews exploration goals or procedures (Sklar 2004).

Secondarily, studying crew practices focuses on operations rather than logistics. In contrast, many of Larson \& Balogh's (1999) studies about EVAs, communications, life support, etc. focus on hardware alternatives (e.g., the 'data budget' for transmitting between Earth and Mars). My focus in MDRS5 was understanding first of all how people work together and how to facilitate their interactions. These starting points correspond to different perspectives for designing automation (Zuboff 1988): The "automate" view seeks to replace a person (e.g., a robotic geologist). The "infomate" view seeks to facilitate human awareness, understanding, communication, and learning (e.g., a robot that monitors astronauts for safety during an EVA).

\section{DATA COLLECTION AND ANALYSIS}

Allowing for a day of moving in and handover from the previous crew, rest on the middle Sunday, a media open house day, and a clean-up day before departure, there were ten actual simulation daysMonday-Saturday of the first week and Monday-Thursday of the second week.

We were alone during the formal simulation, except for two short visits by a contractor resupplying fuel and water. Mission-oriented (non-personal) communications were by email, restricted to a single point of contact, called capcom ("capsule communicator," a NASA term stemming from the Mercury program). Capcom and the rest of the mission support staff were members of the Northern California Mars Society. All reports, requests, and assistance was first directed through capcom. By protocol, after a secondary contact was established (e.g., someone to advise our work on the greenhouse), further conversations on the same topic were not mediated by capcom, but were always copied to him.

In carrying out the ethnographic study, knowing in advance that questions about productivity, planning, and layout were of interest, the following data were collected:

- Time lapse video of upper deck throughout the rotation (every 3 second, 320x240 pixels) from 730 am until midnight (or on several occasions until everyone was asleep)

- Video recording with sound of all planning meetings

- Log of crew location and activities every 15 minutes on two consecutive days ("snaplist")

- Personal crew logs of awake and sleep times, plus time devoted to galley operations

- Written plan of daily proposed and deferred tasks in a table by date and person

- Written crew (“post-occupation”) surveys

- 97 reports posted on the web, with completion dates, including commander's daily log and health and safety officer's (HSO) daily reports

- Approximately 1000 time-stamped digital photographs. 


\section{Effect of scheduling on productivity}

In contrast with a conventional time-and-motion study, the use of time lapse is not focused on a particular job, but on how people are living in the habitat. The analytic method is exploratory, to determine what can be learned from such video data about use of space, affects of collocation (e.g., different people doing different activities in adjacent areas), "off task" activities (e.g., reading a manual while snacking), informal assistance, etc. The focus is not on identifying inefficiencies, but rather revealing activities, motivations, and interactions - and especially their productive value-that were unknown or unappreciated.

In this study, I found that time lapse video is highly useful for answering the question "where does the time go?" We proceed by considering what time is available, subtracting sleep time, group activities (especially meals and EVA operations), and unscheduled interruptions (especially power failures).

To begin, chores were formally assigned to share the work on a rotating basis: Individuals were assigned to manage the galley (cooking and cleaning), to refuel the gas-powered generator, and to assist with refueling. Each person had five to eight days with one these responsibilities, allowing for concurrent tasks and extra assignments to fill the schedule (e.g., the HSO accepted three extra generator days). The actual time devoted to galley operations varied between approximately 200 minutes and 350 minutes per day, with an average of 4 hours 23 minutes (Figure 1). The two people assigned to refueling the generator spent about 45 minutes a day (every eight hours).

Sleep duration varied between 8:09 and 6:21 (h:mm, Figure 2), most strongly affected by the late evening movies and required attendance at the 9 am planning meeting (4/14 was the Sunday without a meeting).

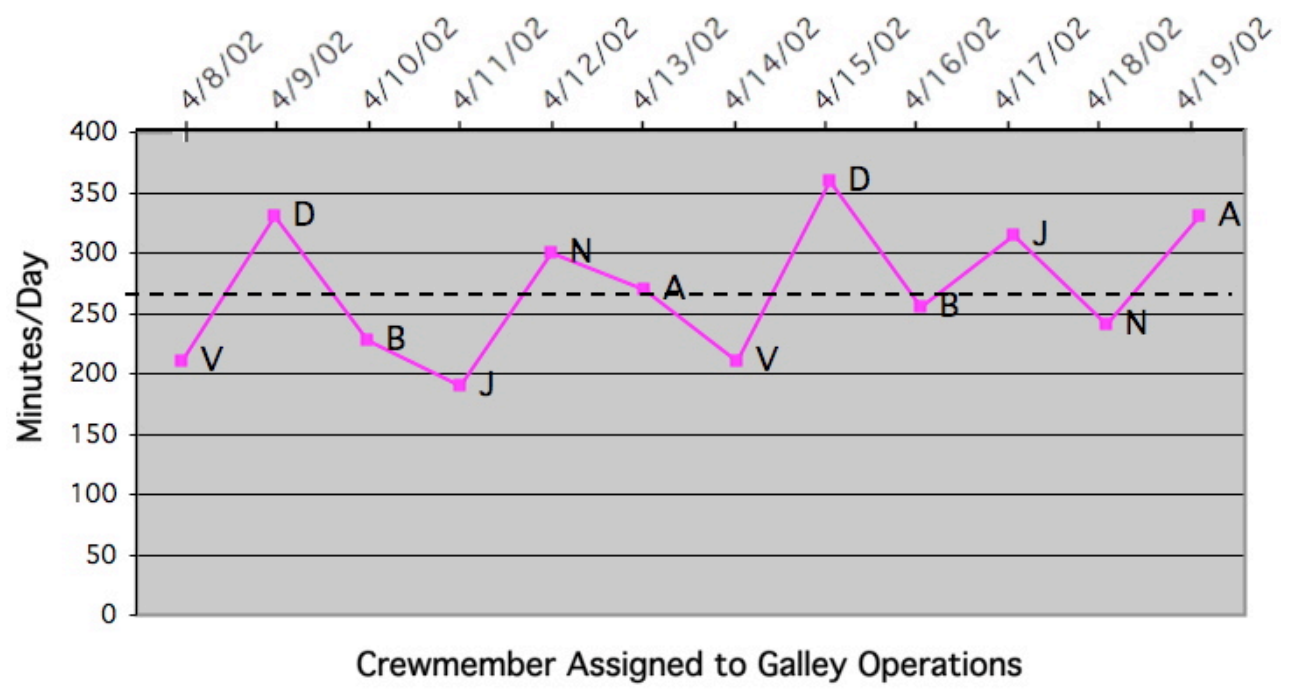

Figure 1. Total time devoted to galley operations by the assigned crew member, April 8-19; average 4 hrs 23 minutes (e.g., crewmember $\mathrm{V}=210$ min. on April 8).

The extent of group activities including meals, meetings, movies, etc. can be determined within a few seconds accuracy from the time lapse record. The camera was placed on a tripod (Figure 3), using a wideangle lens. As previously reported (Clancey 2001a), the frames are examined manually, creating a spreadsheet of events and start/stop times, which is then processed by a computer program to produce tables for graphing. The total time available to each person to work inside the habitat - taking into account their sleep, time devoted to chores, EVAs (and assisting others), lost time from power failures, movies, lunch, dinner, and meetings-averaged 10 hours 37 minutes. The minimum was 9:15 (crewmember A), the maximum 11:30 $(\mathrm{N})$, a range of two hours. The other times were: B-10:11, J-10:35, D-10:57, and V-11:16. These figures do not include irregular chores (helping the fill the water tank every few days), personal hygiene, or breakfast. Strikingly, when allowed to sleep as required and personally 
vary the time allocated to assigned chores, crew members do not have the same time available to do individual work. Crewmember $\mathrm{N}$ has the most time because she participated in fewer and shorter EVAs. A has almost 1.5 fewer hours available per day, which must be considered in evaluating her sense of frustration at lacking enough time to do her work.

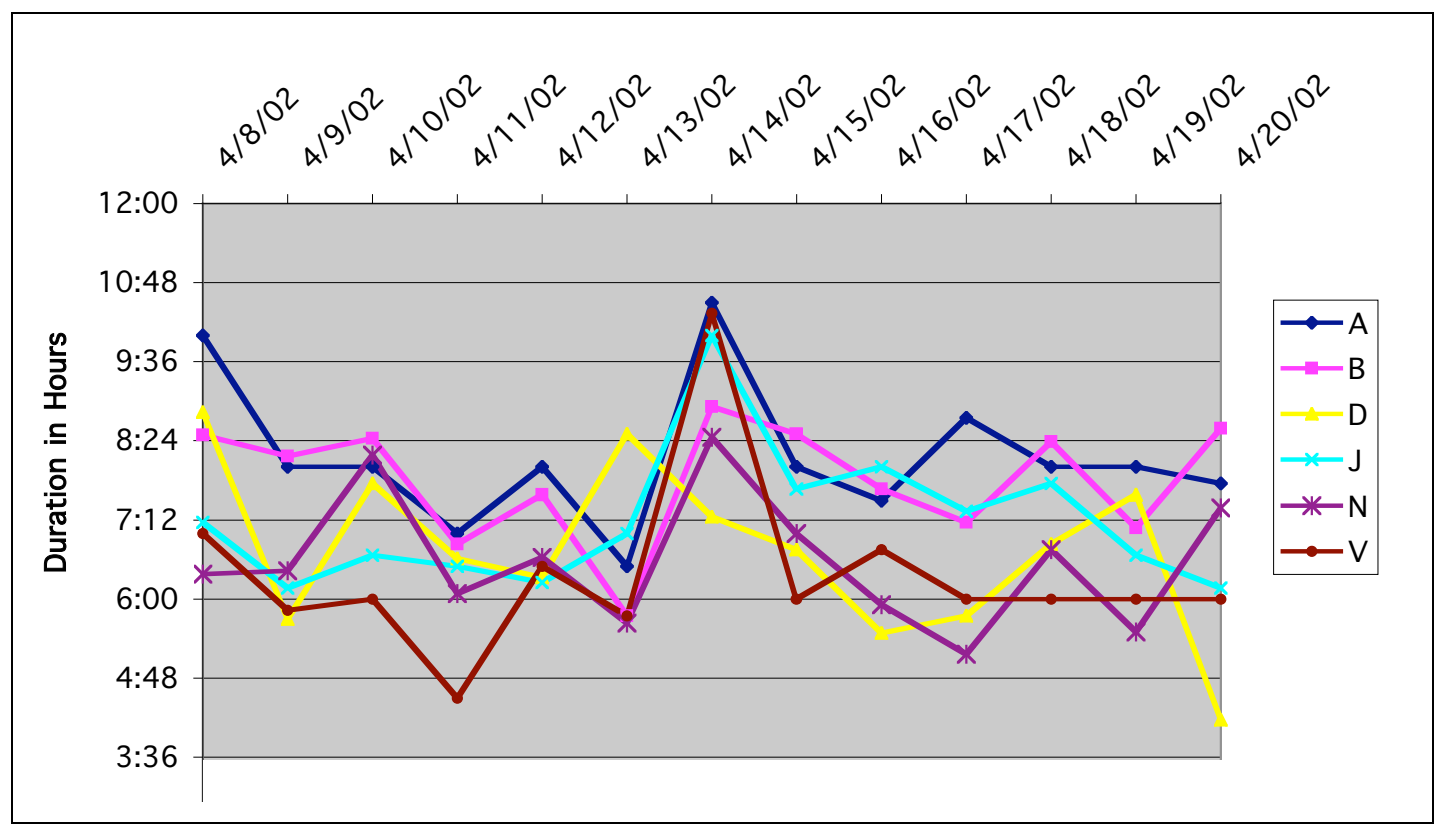

Figure 2. Sleep duration by crewmembers
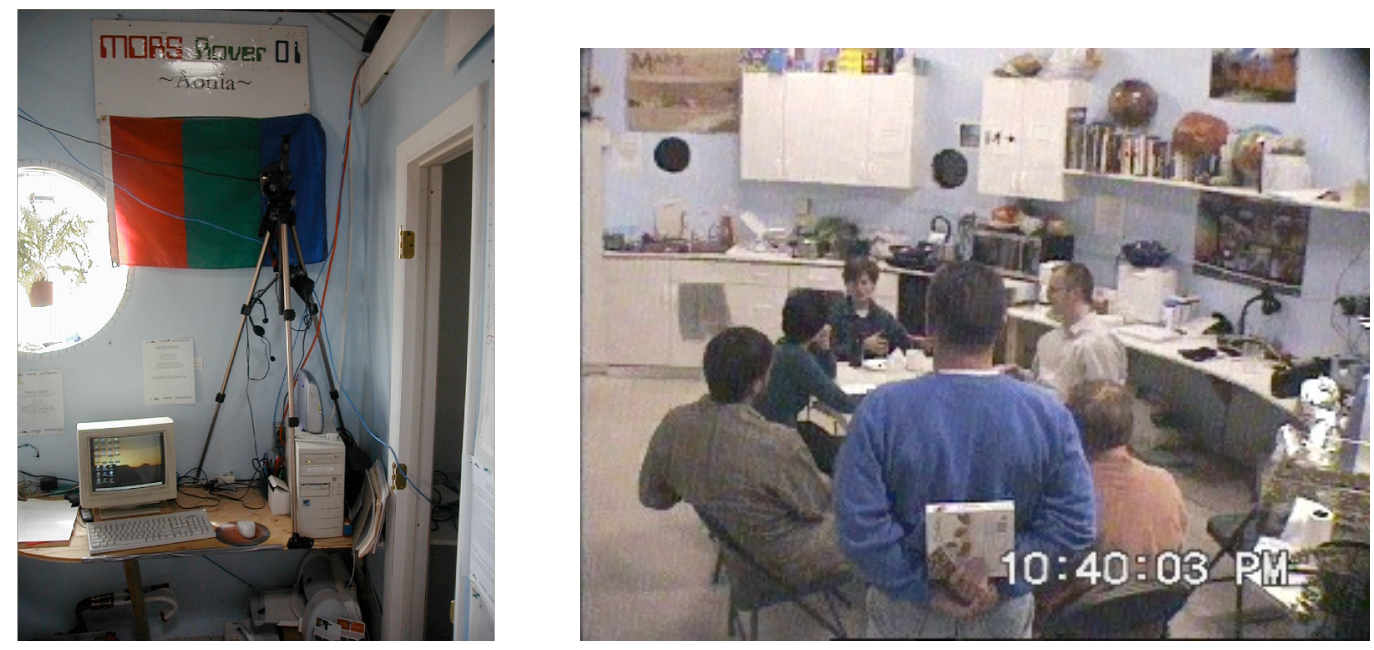

Figure 3. Video camera set up for time lapse recording, with an example frame (Pletser is about to surprise the group with a box of candy)

To this point, we can relate individual differences and understand roughly how much time is available for laboratory analysis, writing reports, and so on. The initial question of "where does the time go" is now all the more mysterious. Why did the group report at the planning meeting on the fourth day (4/11) not having enough time, when everyone has at least nine unscheduled hours per day, and the average is 10.5? What the averages disguise is the change that occurred after this meeting (see Daily Schedule, Figure 4). 
Creating the daily schedule chart was the most pivotal part of this analysis. It shows trends that were not visible or even known to members of the crew, such as how having dinner earlier leaves open time for additional work before starting the movie. This graphic helps us understand at a glance how scheduling changes how much time is available when it is most needed, especially before and after dinner. The chart also makes us more aware that people do not operate on a 24 hour day (except for perhaps the journalist); every hour is not equally available for doing productive work. In practice, only the time between 9am and $10 \mathrm{pm}$ is universally available. Some people may rise early and work on e-mail before 9am and others may work well past midnight. But if we are to understand how group scheduling affects productivity, we need to shift from studying individual averages to considering what time is practically available for everyone. Also, we need to examine the data in terms of variables that changed, looking for effects on productivity.

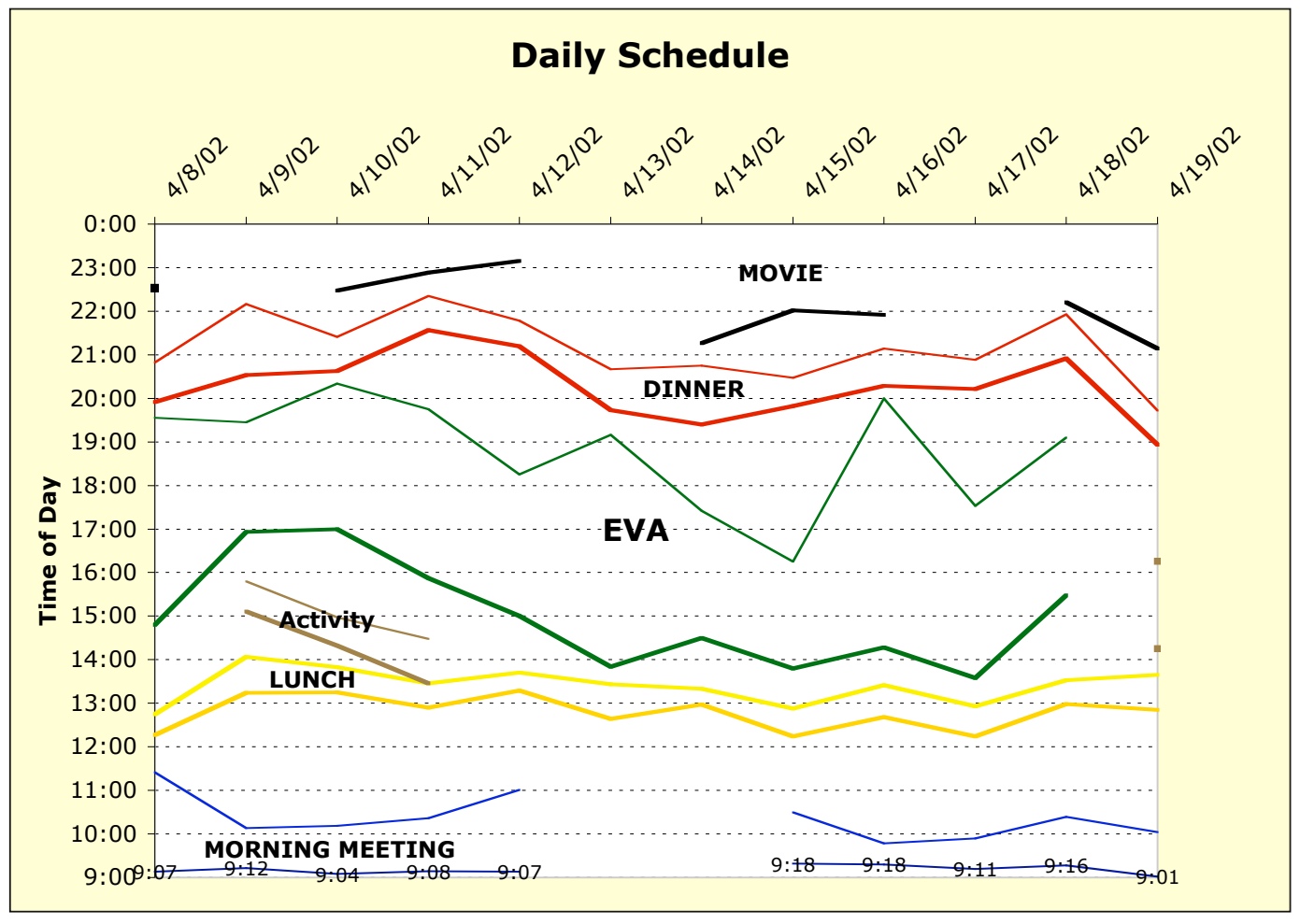

Figure 4. Extent of regular group activities (colors correspond to start and stop times of each activity, e.g., on 4/8 dinner began about 20:00 and ended about an hour later; only movie start times are marked).

Figure 5 reorganizes the daily schedule data to show what time is equally available to everyone, comparing the two five-day periods previously described, omitting the rest, cleaning, and open house days. Productivity is increased by shortening the morning planning meeting and eliminating the afternoon tutorial activity. Again, we shift here from studying individuals to studying the resource available. Furthermore, productivity metrics can't be absolute; we must compare something. Given that the group discussed its productivity problems on the fourth day, a comparison of the first five days to the second five should reveal a significant cumulative change. In summary, our objective here is to measure a valuable resource that schedule changes (for example) might have affected.

What other changes might be useful? Lunch is already short (about 40 minutes); more might be lost in group cohesion by eliminating it as an organized activity. By making dinner earlier, more productive time is available in the evening. In the first week, the group worked as hard after dinner, but had to do this by watching the movie later or skipping it. This effort probably cannot be sustained; one might further argue that 13 hour days are too long. 
Notice that the shorter meeting time allowed an earlier lunch, plus it provided more work time (tempered somewhat by starting the meeting later). In turn, the EVA could be scheduled earlier (helped by improved weather that made waiting for the cooler part of the afternoon unnecessary). Furthermore, the increase in productive time after EVAs is not at the expense of EVAs, which increased by $53 \%$ total person hours. Thus predicting time available from a schedule change is not a simple matter of adding up the pieces (e.g., reduced group time is translated directly into individual time); length of EVAs in particular is highly variable and here evidently expanded to fit the time available.

In summary, we shortened the morning meeting (most likely because less planning was necessary), we had earlier (but not shorter) meals, and we eliminated the after lunch "tutorial." In this analysis, time after $10 \mathrm{pm}$ is not deemed as available (not useful for getting work done). An important consequence of shifting the day downwards was that movies could begin earlier (by $10 \mathrm{pm}$ ) and people could get to bed sooner (by midnight). This lowered fatigue on the subsequent day and increased the number of proposed tasks at the planning meeting.

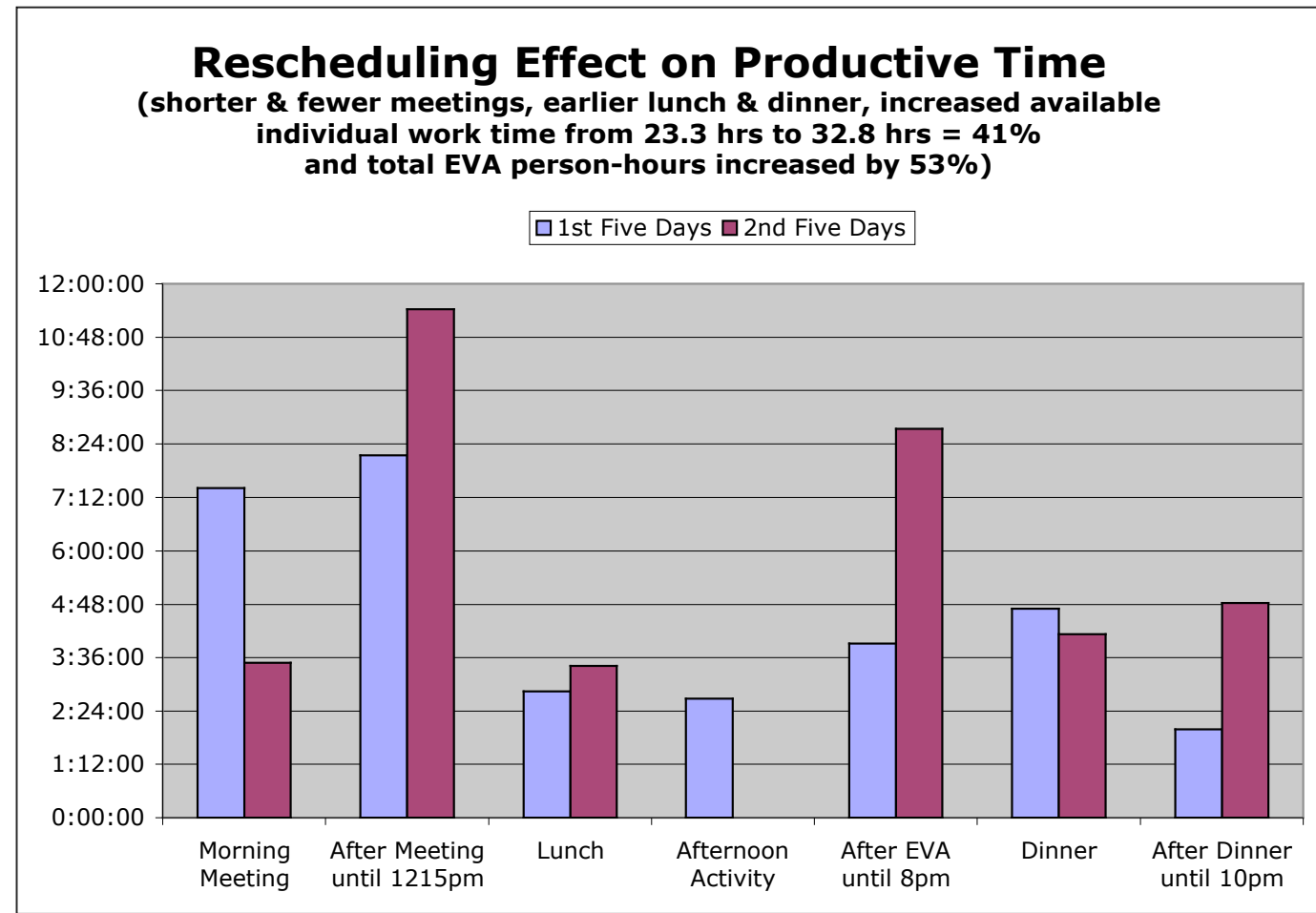

Figure 5: Affect of rescheduling on individual's available productive time (9am-10pm), shown as time in hours for daily activities.

\section{Productivity Metrics}

To this point we have considered only how much time the crew worked per day and how the schedule affected available individual time. Can we measure directly what the crew accomplished? I consider here the crew's reporting activity and to what extent daily plans were completed.

\section{Report Writing}

The crew wrote 97 reports over 12 days, totaling 57K words (for all MDRS reports and photographs, see www.marssociety.org/MDRS/2002Dispatches/). Number of words written per person falls evenly into three groups: the commander and ESA Scientist each wrote $29 \%$ of the total; HSO and journalist, $14.5 \%$; biologist and geologist, 6.5\%) - a ratio of 4:2:1. The commander, HSO, and ESA scientist wrote extensive daily logs (including French translations, not included in the total); the biologist and geologist 
wrote daily activity notes and weekly reports; and the journalist wrote five crew bios and two daily life stories. The number of words increased by $26 \%$ in the second week, with the most on the last Friday, suggesting an end-of-mission "completion effect" of submissions by the scientists and journalist (Figure $6)$.

Although people may vary in how quickly they write, the distribution fits individual accounts of how they spent their time alone. Previous simulations (Clancey 2001b) have shown reporting, because of the daily deadlines, to require much more time than expected, and to be the chief reason for working into the evening. The shorter reports of the scientists reflect their focus on data and interpretation, as opposed to comprehensive story telling. ISS crews and NEEMO aquanauts have written logs, in contrast with formal reporting for scientists, as undertaken in FMARS and MDRS simulations. The use of word counts here is of course not meant to be a value judgment of accomplishment, but to provide basic data that missions schedulers need to consider, as well as to raise awareness among researchers about this essential activity. For example, the wide distribution of reporting effort underscores that understanding productivity of the crew requires considering choices individuals make, as well as differences in their roles. Together these will produce different reactions from the time pressure of group activities.

\section{Daily Total Crew Report Words Completed ( $26 \%$ increase in second week)}

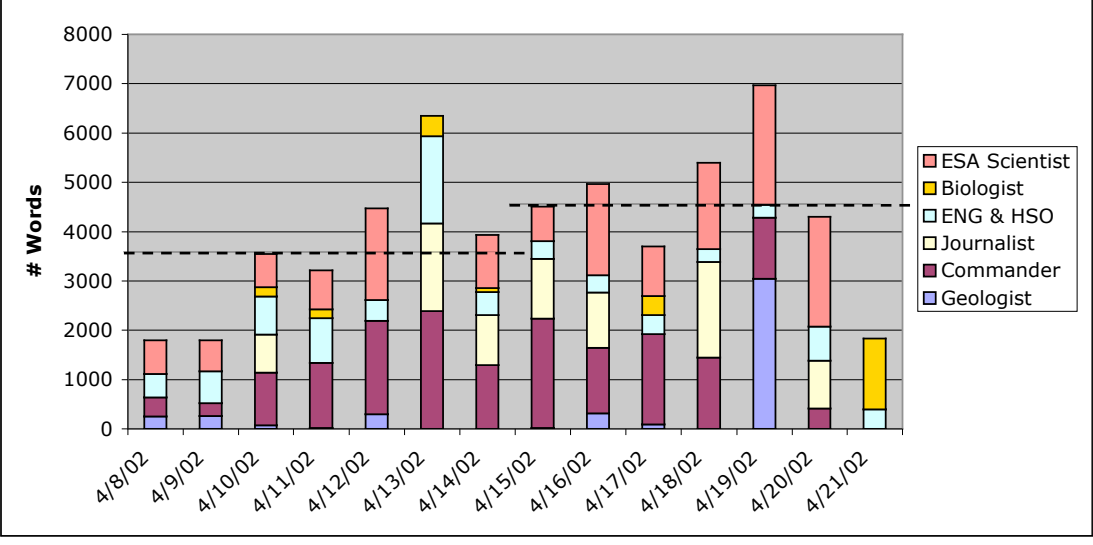

Figure 6. Total number of words in reports released for web publication by the MDRS5 crew per day.

\section{Task Productivity}

Experience in FMARS simulations (Clancey 2000b, 2001b) suggested further study of how the crew plans daily activities. Each day the commander edited a table in a word processor to indicate what each person planned to do. Tasks were copied over from the previous day as necessary, with text changed to a strike-out font, to indicate lack of completion the previous day. Different formats were tried; the use of a simple table with one column per person and extra columns for group activities worked best (Table 3). These plans were analyzed by tallying the number of tasks proposed and deferred each day (Figure 7). On average two tasks were proposed per person/day; 60 were completed in the first six days, 72 in the second.

Table 2. Plan for Saturday, April 13 (strikeouts for previous day indicate tasks that were not started or abandoned; repetitions such as A's "EVA64 report" indicate continued work; DGO = galley operations; $\mathrm{EOA} \& \mathrm{EOP}=$ refuel generator).

\begin{tabular}{|c|c|c|c|c|c|c|c|c|}
\hline DATE & EVA & $\mathbf{A}$ & B & D & $\overline{\mathbf{J}}$ & $\mathbf{N}$ & $\mathbf{V}$ & All \\
\hline $\begin{array}{l}\text { Friday } \\
4 / 12 / 02\end{array}$ & $\begin{array}{l}67 A, B, D \\
\text { Find Oyster } \\
\text { route, photo }\end{array}$ & $E O A$ & $\begin{array}{l}\text { Must learn to use } \\
\text { GPS, print map } \\
\text { or take REI map }\end{array}$ & $\begin{array}{l}\text { Hill } \\
\forall \\
\forall\end{array}$ & $\begin{array}{l}\text { UPS } \\
\text { debugging } \\
\text { J will read }\end{array}$ & $\begin{array}{l}D G O \\
\text { Will write }\end{array}$ & $\begin{array}{l}\text { EOP } \\
\text { Datalogger } \\
\text { to Capcom }\end{array}$ & $\begin{array}{l}\text { Fire } \\
\text { drill } \\
\text { with }\end{array}$ \\
\hline
\end{tabular}




\begin{tabular}{|c|c|c|c|c|c|c|c|c|}
\hline $\begin{array}{l}\text { Isolated } \\
\text { T-storms } \\
79\end{array}$ & $\begin{array}{l}\text { collection } \\
N \text { ' windsock } \\
\text { and dry-site } \\
\text { collection } \\
\text { Pedestrian } \\
\text { EVA before } \\
67\end{array}$ & $\begin{array}{l}\text { Write } \\
\text { EVA64 } \\
\text { report }\end{array}$ & EVA plan with $A$ & $\begin{array}{l}\text { "What } \\
\text { are these } \\
\text { people } \\
\text { doing } \\
\text { there all } \\
\text { day?" }\end{array}$ & $\begin{array}{l}\text { Biolet } \\
\text { manual }\end{array}$ & $\begin{array}{l}\text { bio report } \\
\text { Needs } \\
\text { mostly dry } \\
\text { sample } \\
\text { from dust } \\
\text { catchers }\end{array}$ & $\begin{array}{l}\text { \& Gus } \\
\text { Write GH } \\
\text { report on } \\
\text { Ecologger } \\
\text { \& watering }\end{array}$ & $\begin{array}{l}\text { pump } \\
\text { after } \\
\text { mtg }\end{array}$ \\
\hline $\begin{array}{l}\text { Saturday } \\
4 / 13 / 02 \\
\text { Predict: } \\
\text { Mostly } \\
\text { sunny } \\
81\end{array}$ & $\begin{array}{l}68 \text { J, V, D } \\
\text { Mid-Ridge } \\
\text { Planitia } \\
\text { Loop } \\
\text { (marking \& } \\
\text { finding } \\
\text { waypoints) }\end{array}$ & $\begin{array}{l}\text { EOP \& } \\
\text { DGO } \\
\text { Update } \\
\text { EVA } \\
\text { calendar; } \\
\text { Waypt } \\
\text { sheets; } \\
\text { send } 5 \text { geo } \\
\text { rpts; } \\
\text { EVA64 } \\
\text { map \& } \\
\text { coords; } \\
\text { Primer }\end{array}$ & $\begin{array}{l}\text { Review GPS } \\
\text { msgs; define an } \\
\text { EVA "failure" } \\
\text { experiment; } \\
\text { Geo books } \\
\text { pictures? } \\
\text { Photos from } \\
\text { loft } \\
\text { Doubletalk }\end{array}$ & $\begin{array}{l}\text { EOA } \\
\text { Will } \\
\text { interview } \\
\text { V }\end{array}$ & $\begin{array}{l}\text { Help N w/ } \\
\text { camera. } \\
\text { teach A } \\
\text { how to } \\
\text { create map } \\
\text { from } \\
\text { TopoUSA; } \\
\text { Send audio } \\
\text { file from } \\
4 / 12 \text { mtg }\end{array}$ & 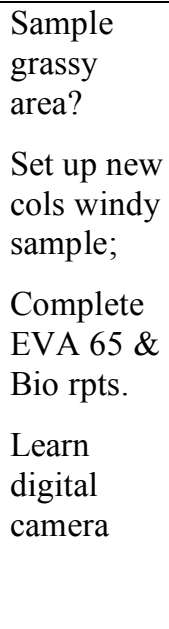 & $\begin{array}{l}\text { Reformat } \\
\text { pics in } \\
\text { Science } \\
\text { report }\end{array}$ & $\begin{array}{l}\text { Latest } \\
\text { day to } \\
\text { refill } \\
\text { water }\end{array}$ \\
\hline
\end{tabular}

Referring to Figure 7, note that April 14th is Sunday, the rest day. A strikingly even number tasks are proposed (15/day) with many additional tasks in the last week for wrapping up projects. Group tasks include EVA objectives, tutorials, and drills. Like counting report words, this measure is very crudesome tasks take a few minutes, others take days. Nevertheless, the comparisons between days should have some validity. Excluding the day of rest, whenever the group as a whole slept more than the previous night (4/10, 4/12, 4/18), the number of completed tasks increased compared to the day before. Otherwise, when the crew slept less $(4 / 9,4 / 11,4 / 13,4 / 16,4 / 17,4 / 19)$, the number of completed tasks decreased or stayed the same. 


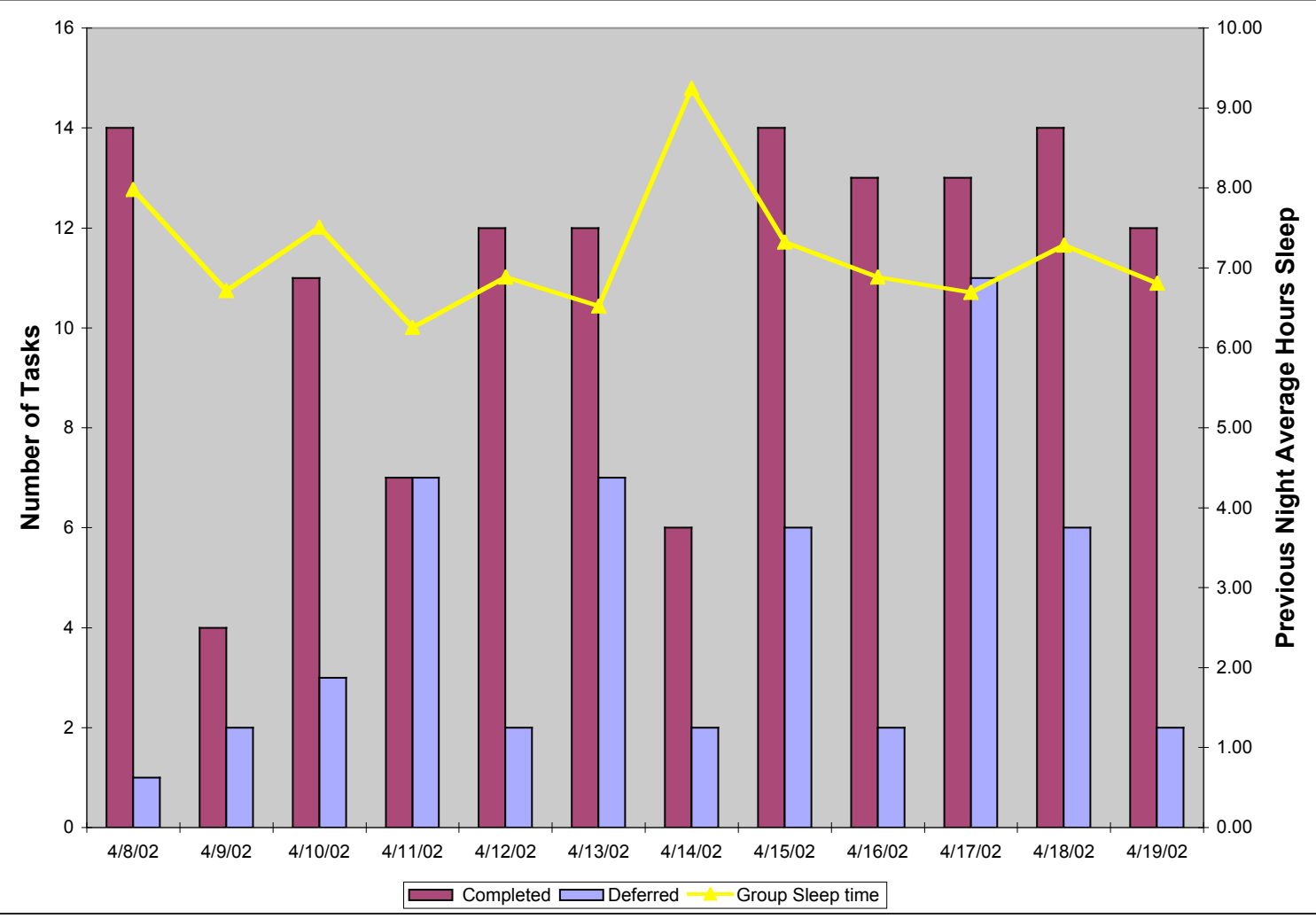

Figure 7. Number of tasks completed and deferred each day, plotted against average sleep time per person.

\section{Layout and Use of Space}

Because no visitors were allowed inside the habitat during the 10 day closed simulation, we can completely characterize how space was used. The time lapse allows in principle determining, for example, when and for how long people used their staterooms. Methods are being developed to automate this analysis using image processing and other localization techniques (Figure 8).

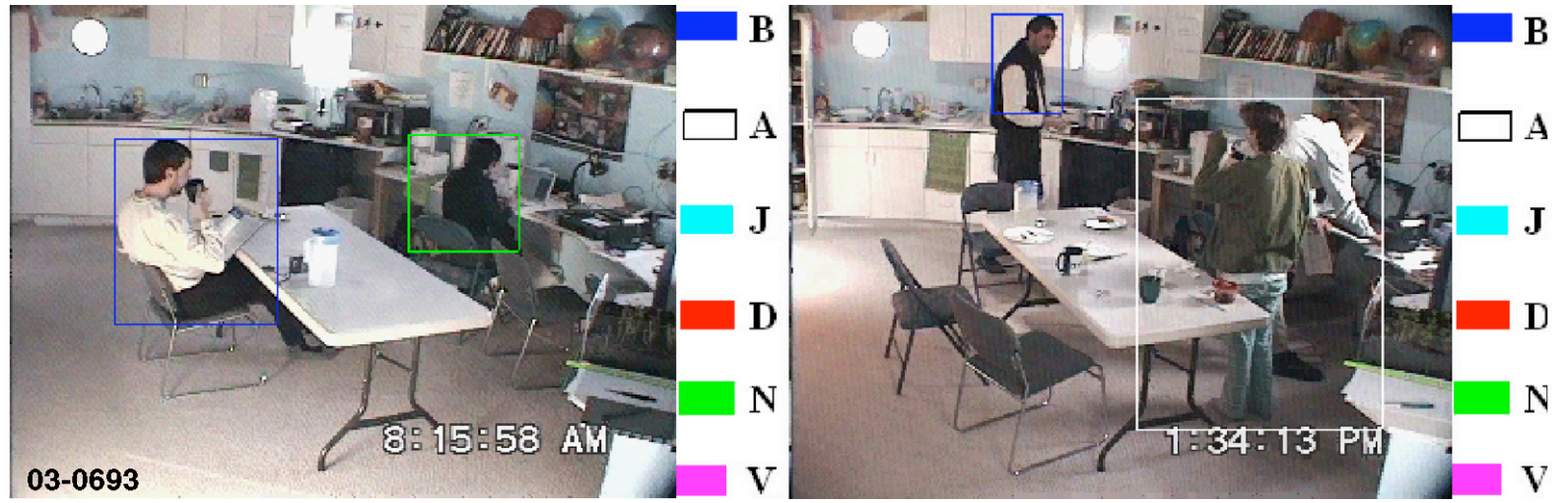

Figure 8. Sample results of Crew Activity Analyzer. Each crew member's position, size, and color map were tracked for a full day of MDRS5. (Courtesy of Foster-Miller, Inc.)

Foster-Miller's Crew Activity Analyzer separates crew members from the background by detecting motion and using image segmentation. A full day was analyzed to determine: Presence and absence of crew, number of visits to the visible area, and percentage of Time spent in the area. The frame rate and 
program limitations in recognizing people by the clothing limited accuracy to $80 \%$ (compared to manual analysis), but this is still highly valuable for indexing the video.

To complement the video record, which did not include the lower deck, a paper record was kept of where people were and what they were doing every 15 minutes over a period of one and a half days (Figure 9). After this time, the patterns were obvious and it was clear that additional recording (at the 15 minute grain size) would provide little or no further information.

Direct observation showed that each person tended to spend most of their time in only a few (two to four) places. The three people with internet connections in their stateroom $(B, D, V)$ spent most of the day there (A used the stateroom to read before dinner; on other days $\mathrm{J}$ used his upper bunk as a work table). Of the other three crew members, two (A \& J) worked at the workstation bench of the upper deck (where they could connect their computers to the internet); on this day $\mathrm{N}$ was more often found in the laboratory of the lower deck. On this day D was responsible for the galley. The mess table, used for meetings, meals and video, was used evenly by everyone. ("Outside" refers to required work without suits; J worked with the water pump; B photographed an EVA activity.)

Comparison across two days showed fairly consistent use of space. About $25 \%$ of the day is spent sitting at the mess table. The lower deck is obviously underutilized; it is occupied only $8 \%$ of the time (though many visits to the toilet were not observed in the 15 minute interval).

Data about use of space can also be used to measure how often people move around. A "move" is defined as a person changing location from one 15 minute observation to the next. The first day has 52 observations; D moved the least, 17 times; V moved the most, 28 times; the average is 21 . The second day has 69 observations; A moved the least (17); D moved the most (30); the average is 23. Further data are required to establish individual differences, if any. A person may also be very reactive - prone to get or check something when the idea occurs to him or her. Such short and frequent movements would not be caught by the 15 minute grain size. Foster-Miller, Inc. is working with NASA to develop a complete crew tracking system that will experiment with radio frequency identifiers (RFIDs).

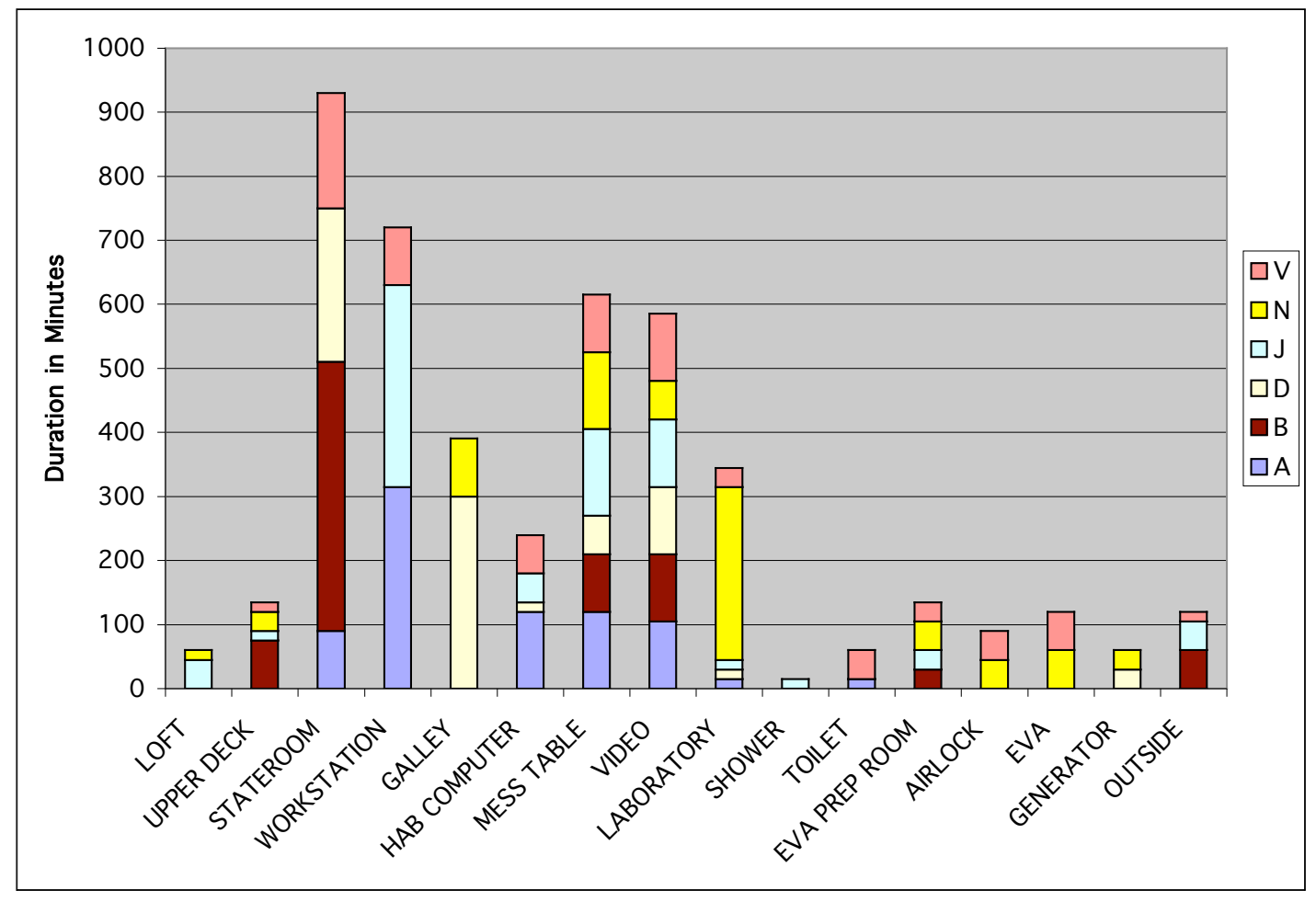

Figure 9. Total time in each location by person, MDRS5 11:15-24:00 April 15, 2002 
From the perspective of work practice studies, data about use of space and movements provides a kind of background against which one might understand other observations or crew complaints. For example, N's time in the laboratory, combined with showing up late for the evening movie session (visible on the time lapse), indicates a time pressure that others at first sloughed off as "not wanting to be part of the group." V's moving around inside the hab, by contrast, is perhaps consistent with someone who values difficult EVAs. These issues surfaced in the crew post-occupation survey.

\section{Crew Post-Occupation Survey}

Crew members completed an individual written survey after the closed simulation ended. For the items ranked by importance, the most important (average rank $>=4$ on 1-5 scale) were clean drinking water and sufficient power, closely followed by diet, adequate EVA suits, and toilet. Ranked next were free time and showers.

From the open questions, the following patterns are apparent:

1. Everyone observed that the crew interacted harmoniously; reactions to each other were without exception upbeat and cheerful.

2. Everyone reported either insufficient time to accomplish objectives and/or inadequate leisure time: Computer network problems and/or interruptions are cited by everyone, but only two people mention unnecessary report writing (in such a simulation, the audience can be ill-defined).

3. Four out of six (4/6) said the most important problem is the toilet facility (followed by power).

4. Providing stable, sufficient power, without refueling would have the greatest effect on morale and productivity.

5. Tool usage posed problems were cited by everyone, either from lack of access to a tool (computer or camera), lack of knowledge to use a tool, or being interrupted by requests for assistance to use a tool.

6. The best moments were outdoors (5/6), with three people mentioning a particular EVA in which they participated together (this is remarkable given that surveys were privately prepared).

7. The worst moments were all different and had no resemblance to each other (e.g., as commander, my worst moment was when a crew member felt ill during dinner; nobody else mentioned this event, not even this crew member).

8. For those having a computer connection, the stateroom was an important place, for others it was just a place to sleep; half mentioned the importance of privacy.

9. Everyone wanted a better EVA suit and more than one shower/week.

10. Everyone would have continued a third week; everyone would stay for a month if family and work allowed.

11. Food and habitat temperature were not issues for this rotation.

12. The group provided varied and imaginative ideas for habitat improvement, with a surprising number of suggestions focusing on kitchen equipment.

In response to the question of "where did the time go," every crew member would try to change how they used their time on subsequent simulations:

- Geologist: wanted to find a way to work uninterrupted for longer periods of time; couldn't concentrate on reading and writing.

○ Commander: never read any of the crew's reports, too much time writing logs. 
- Journalist: didn't write enough "daily life" stories; on reflection would have done this instead of writing biographies.

- Health and Safety Officer : too much time being "Mr. Fix-it"; didn't have time to model the habitat as planned.

- Biologist: insufficient lab time, too much group time (ironically, this person had the most amount of available individual time per day, considering sleep, EVAs, and chores).

EVA Scientist: insufficient EVA time, too short and lacking adventure.

Individual differences in what individuals didn't say are also intriguing:

- Only one person (the commander) didn't complain about lack of time (rather I wanted entire days off, to do something entirely different).

- Only one person (the journalist) didn't mention outdoor activities as a highlight.

- Only one person (the biologist) didn't complain about interruptions or network problems, perhaps because she spent so much time working alone in the laboratory, away from her computer.

- Only one person (the EVA scientist) didn't complain about the toilet and mentioned the importance of skill training in advance (reflecting his professional experience).

These differences may reflect mood or experience on the day of the survey. In any event, we are reminded that individuals will react differently to identical circumstances, sometimes because of different roles, but also because of temperament and past experience. The comments highlight that differences must always be expected, even in a crew that experiences itself as being especially harmonious. Further, over a long mission, the crew might enjoy varying its routine, so for example, one person could be left alone to work and eat independently for a day or a week, according to his or her personal need for concentrated effort and variety.

\section{DISCUSSION: SYSTEMATIC WORK SYSTEM DESIGN}

This section summarizes the framework of analysis and modeling that orients the empirical study carried out in MDRS5 and comments on how the analysis is informing ongoing research on work systems design (Clancey, et al. 1998; Clancey, 2001b, in press; Sierhuis, 2001). In this context, the work system (Figure 10) refers to the design of the MDRS habitat and its tools, the crew's roles and assignments, the daily schedules, protocols for interacting with mission support, and practices for using the habitat, tools, and interacting with each other.

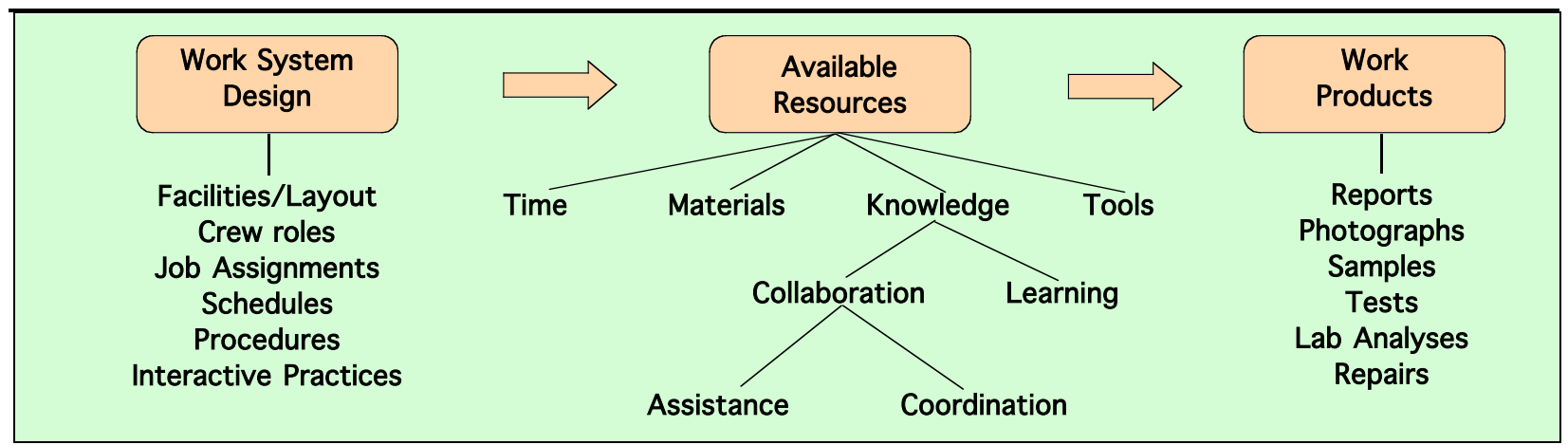

Figure 10. Different work system designs (facilities, tools, crew roles, etc.) affect the resources available, which affects the quality and quantity of work products. 
The framework suggests that, in order to understand how a given work system design causally influences productivity (the quality and quantity of work products), work system studies should focus on changes in resources brought about by schedules, facilities, roles, processes, etc. For example, this paper has shown how the crew's change in the daily schedule, prompted by a desire to be more productive, resulting in a significant increase in the amount of time available for individual work, such as report writing. The next step is to show how a change in resources actually affected work products (e.g., number of samples processed).

Another approach is to eliminate tasks by changing how the work is done. In particular, during this MDRS5 the crew was required to learn and use GPS devices for planning and logging EVA routes. This required time for training (e.g., the afternoon "activity" 4/10, Figure 4), preparing routes using maps and previous EVA records, logging coordinates in the field, and documenting routes in EVA reports). The fundamental ethnographic result of the MDRS5 study, directly influencing software tool design-indeed, fully reconceiving how EVA operations were managed - was to eliminate the use of GPS devices by the crew. This idea appears in my log on Monday, April 15:

At this time, I sent an email to my colleagues at Ames. I want them to begin thinking about designing software that will make the GPS unit fully invisible to an explorer. I don't want to wait for a satellite fix; I don't want to transcribe readings. I don't want to ever know the coordinates at all, let alone have to manually enter or compare them or number waypoints. I want a program to answer questions while I'm on EVA: "Has anyone taken samples near here before?" I also want the program to tell me things like: "Warning, you are within 10 minutes of the reserve fuel supply required for safe return to the hab." Being here at MDRS this past week has given me very clear ideas about the navigation assistance and other monitoring required during remote exploration on ATVs. Until now, back at Ames and JSC, we weren't sure what to build; we had the methods, but not the requirements. That's why I call what we are doing here "empirical requirements analysis"finding out what you need to build by doing simulations in the field.

The result is a system called "mobile agents," which has now been field tested at two subsequent MDRS rotations (Clancey 2004a,b). Instead of building a better GIS interface for tracking routes, improving the displays and buttons on the GPS devices, or off-loading the work to mission support, observing the work practice first hand suggested that we simply eliminate the entire discourse of coordinates from EVAs. Using Mobile Agents, an astronaut can name places ("Call this place work site five"). The system automatically associates science data (photographs, samples, voice annotations) with named places and organizes the data in a database in the habitat, mirrored back to a remote science team.

The GPS example illustrates how requirements for computational systems should be developed contextually, in tandem with broad operations experiments like MDRS5. In contrast, Persaud (2004) argues for using "the scientific method" to break mission operations into parts, constructing controlled experiments whose parameters can be quantitatively measured. Unfortunately, the cause-effect, subsystems decomposition approach, which is appropriate for engineering some kinds of systems, does not work for understanding and improving work practice, including especially computer tools. Work system interactions are non-linear, highly contextual, and increasingly decentralized (Senge 1990; Malone 2004). Imposing "strict experimental controls" to understand people may prevent natural interactions from developing that are crucial for handling unexpected situations. Optimized designs developed from narrower investigations cannot necessarily be combined. For example, introducing a new maintenance task into the habitat environment provides new interactions that must be contextually understood. This is particularly true because people and some technical systems are adaptive, and it is the coping mechanisms we need to understand and shape. 


\section{CONCLUSIONS AND NEXT STEPS}

The Mars Society's research stations provide a unique opportunity for preparing for Mars missions by virtue of providing authentic exploration for field science in a Mars analog environment, a habitat with size and layout influenced by a Mars Reference Mission (Hoffman \& Kaplan 1997; Zubrin 1996), relative isolation from other people, and crewmembers who are interdisciplinary scientists and engineers knowledgeable about spaceflight. The emphasis presently is not on training, but imaginative investigation, experimentation, projection of experiences into the requirements and operations of an actual Mars mission.

The fifth rotation of MDRS met its objectives - in field science, in reporting, and in the study of human exploration. This rotation introduced a number of creative innovations to the Mars Society's analog program: the closed simulation protocol, systematic recording of the entire rotation, preliminary specification of an "automated capcom" EVA communications system, and many improvements to the habitat (most notably the bread maker). The data recording methods were entirely successful, allowing discovery of unexpected trends in group behavior, showing how schedules influence productivity. The analysis has also been related to ongoing work in work practice simulation (Clancey et al. in preparation) to show how statistical data informs modeling, while revealing questions for further observation.

Of paramount importance, given the effort and expense to build a research station like MDRS, is determining what can be learned from an analog activity and how the activity should be managed and studied as a scientific investigation. By analyzing field notes, time lapse video, task plans, activity logging, and surveys, we made the following findings from the MDRS5 simulation:

1. Adjusting the group activity schedule creates more useful time for working (before lunch, before and after dinner). When astronauts are given lists of tasks to do in a day, rather than told what to do at each moment, chunks of time must be available so they are able to complete work without interruption (cf. Leninger 2000, pp. 132-134).

2. Interruptions significantly affect productivity: power failure, group activities, assigned chores, requests for assistance, computer network problems, incoming email. Reorganizing work sites to continue a task wastes time (Leninger 2000, p. 90).

3. Timing and counting activities (systematic recording) is essential for detecting patterns and making work system design recommendations. The process is iterative; a successful outcome is determining what observations need to be made on subsequent simulations. Whereas cross-role comparisons of productivity may be problematic (e.g., number of words written), one can often measure intermediate factors that are universally available for different purposes (e.g., useful time available, table space) and then show how these influence productivity.

4. Tasks involving reading and manipulating data (e.g., a GPS device) are prime candidates for automation. Although the crew reported lack of time as the chief frustration, one solution is to redesign the reporting products required and hence the schedule. Considering the relationship, WSD (e.g., schedule) -> RESOURCES (e.g., time) -> PRODUCTS (e.g., reports), besides increasing resources, one may redefine the outputs required. Eliminating GPS-coordinate manipulations for EVAs using the Mobile Agents system illustrates how radically the work itself can be changed.

In contrast with an engineering or experimental psychology study, ethnographic investigations are viewed as being scientific descriptions, without necessarily a theory to be tested or a design implication. Just as we do not ask a geologist who takes systematic samples on a traverse, "Where is this data going?" a study of the type presented here is be judged partly by its contribution to the broader ethnographic study of field science and habitats. The charts and observations in this paper are only illustrative of the extent of the analyses undertaken or possible. Some events or patterns may only appear significant or be formalized years later (e.g., MDRS5 GPS experience led to analyzing a 1999 video of navigation in Devon Crater 
[Clancey, 2004a]). In particular, the daily reports are an integral part of the data (www.marssociety.org/MDRS/2002Dispatches/); a series of papers could be prepared relating these reports to the work practice questions posted in the introduction of this paper.

This study illustrates several aspects of the work systems design perspective: multiple units of analysis (e.g., considering both group and individual productivity), spatial relations (e.g., task adjacencies-how co-location affects people doing different things), and the benefits of participation (e.g., one can experience firsthand the problem of repackaging daily events into public reports that project a group identity). Regarding the methodological questions posed in the introduction, MDRS5 findings include:

1) Time lapse provided much unexpected data (e.g., calculating time to refill the generator); methods for partly automating analysis are in process.

2) A fulltime participant can carry out ethnographic observation, but writing will require several hours per day. The crew created far more public documents than anyone had time to read.

3) It was possible to use MDRS in closed simulation mode while satisfying needs for safety, maintenance, resupply, and outreach (many MDRS simulations have now adopted the separate "press day").

4) Fifteen minute logs of activity-locations proved useful. It appears impossible to take too many photographs.

5) A closed simulation involving authentic science EVAs at MDRS is especially useful for research on habitat design, crew planning, scheduling, and reporting. Work system design may be viewed as an extension of industrial engineering, using participant observation and emphasizing how work practices continuously develop through the interactions of groups and individuals and their physical-social environment. Referring to the four levels of operations design, office-based workplace studies are more focused on performance and adaptability than survivability and comfort.

As for other scientific studies, generating new questions and study ideas is a mark of success. Possibilities for future research include:

- Use the available time lapse to determine the number of visits and duration of stateroom visits per person.

- Experiment with an internet connection in all staterooms: Does everyone choose to work inside and ignore the outside workstation area?

○ Study interruptions by following ("shadowing") individuals for at least three hour periods. Record the causes, durations, and any apparent disruption in other activity.

- Ask individuals to track time spent on activities of importance to them (i.e., let them decide what to record).

- Provide recorded EVA reports to mission support and let them write the formal reports.

- Compare use of public and private space in MDRS and other habitats.

- Focus on individual's experiences as they plan, learn, and cope with the broader expedition setting.

Although the closed simulation was beneficial for carrying out a systematic study of use of time and space in the habitat, this is by no means the only scientific way to use MDRS or other analog research stations. In particular, one can carry out controlled protocols for shorter periods of time, say a few hours or a day, in which experimental equipment and procedures are used. MDRS's setting makes it especially attractive for research on EVAs, including different configurations of suits, rovers, robotic assistants, agent-based software, local capcom monitoring, and remote mission support (Clancey et al. 2004a, b). 
The relevance of analog lessons to actual missions is complex (Clancey 2000b, 2003), however after four years of habitat rotations on Devon Island and Utah, this much is clear: Hundreds of scientists and engineers have lived and worked together, forming a new community of practice for ongoing research and development. Furthermore, many individuals have defined research trajectories on the basis of projects first attempted at MDRS, and these are wide ranging, including waste water recycling, communications and computing tools, greenhouse sensors and controls, biology lab techniques, geology survey procedures, datalogging devices, and human factors instruments (Zubrin \& Crossman 2002; Zubrin 2003).

\section{ACKNOWLEDGMENTS}

I am especially grateful to the MDRS5 crew for participating in this study. Our work was made possible through the vision, volunteer work, and financial contributions of the Mars Society and its supporters, especially Robert and Maggie Zubrin, Frank Schubert, and Tony Muscatello. Mission support was provided by Mark Klosowski, Frank Crossman, and other members of the Northern California Mars Society. Discussions with Boris Brodsky, the Brahms modeler for FMARS and MDRS, have been very helpful. Related work pursued by Maarten Sierhuis and Alessandro Acquisiti, in simulating how ISS crew members follow schedules, has inspired many aspects of MDRS5 observation and analysis. Patty Jones, Valerie Shalin, Roxana Wales, Barbara Woolford, and the crew members provided many helpful comments for improving this paper. For more information about Brahms see http://www.agentisolutions.com and papers at http://Bill.Clancey.name. Funding for this research has been provided by NASA's Computing, Communications, and Information Technology Program, Intelligent Systems subprogram, Human-Centered Computing element, managed by Mike Shafto at NASA-Ames.

\section{REFERENCES}

Bannon, L. 1991. From human factors to human actors. In J. Greenbaum and M. Kyng (eds), Design at Work: Cooperative design of computer systems. Hillsdale, NJ: Lawrence Erlbaum Associates, pps. 2544.

Bernard, H. R. and Killworth, P. D. 1974. Scientists and crew: A case study in communications at sea. Maritime Studies and Management, 2: 112-125.

Beyer, H. and Holtzblatt, K. 1998. Contextual Design: Defining Customer-Centered Systems. San Francisco: Morgan-Kaufmann.

Blomberg, Jeanette, Jean Giacomi, Andrea Mosher, and Pat Swenton-Wall. 1993. Ethnographic field methods and their relation to design. In Participatory design: principles and practices, ed. Douglas Schuler and Aki Namioka. Hillsdale: Lawrence Erlbaum Associates.

Bradley, G. 1989. Computers and the Psychosocial Work Environment. London: Taylor and Francis.

Britannica. 1987. "Frank Bunker Gilbreth and Lillian Evelyn Gilbreth." Encyclopcedia Britannica 15 edition. Vol 5. p. 265. Chicago: University of Chicago.

Burrough, B. 1998. Dragonfly: NASA And The Crisis Aboard Mir. New York: HarperCollins.

Button, G. \& Harper, R. (1996). The relevance of "work-practice" for design. Computer Supported Cooperative Work, 4, 263-280.

Clancey, W. J., Sachs, P., Sierhuis, M., and van Hoof, R. 1998. Brahms: Simulating practice for work systems design. International Journal of Human-Computer Studies, 49: 831-865. 
Clancey: Participant Observation of a Mars Surface Habitat Mission Simulation

Clancey, W. J. 1999. Human Exploration Ethnography of the Haughton-Mars Project 1989-1999. Presented at the Mars Society Annual Meeting. Boulder, CO. In R. Zubrin and F. Crossman, On to Mars: Colonizing a new world, Burlington, Ontario, Canada: Apogee Books, published 2002, CDROM.

Clancey, W. J. 2000a. Visualizing practical knowledge: The Haughton-Mars Project. (Das HaughtonMars-Projekt der NASA - Ein Beispiel fur die Visualiserung Praktischen Wissens). In Christa Maar, Ernst Pöppel and Hans Ulrich Obrist (Eds.), Weltwissen - Wissenswelt. Das globale Netz von Text und Bild, pp. 325-341. Cologne: Dumont Verlag.

Clancey, W. J. 2000b. A framework for analog studies of Mars surface operations: Using the Flashline Mars Arctic Research Station. Presented at the Mars Society Annual Meeting. Toronto. In R. Zubrin and F. Crossman, On to Mars: Colonizing a new world, Burlington, Ontario, Canada: Apogee Books, published 2002, CD-ROM.

Clancey, W. J. 2001a. Field science ethnography: Methods for systematic observation on an Arctic expedition. Field Methods, 13(3), 223-243, August.

Clancey, W. J. 2001b. Simulating "Mars on Earth": a report from FMARS Phase 2. Presented at the Mars Society Annual Meeting. Stanford, CA. In R. Zubrin and F. Crossman, On to Mars: Colonizing a new world, Burlington, Ontario, Canada: Apogee Books, published 2002, CD-ROM.

Clancey, W. J. 2002b. Simulating activities: Relating motives, deliberation, and attentive coordination. Cognitive Systems Research, 3(3) 471-499.

Clancey, W. J. 2003. Principles for integrating Mars analog science, operations, and technology research. Workshop on Analog Sites and Facilities for the Human Exploration of the Moon and Mars, Colorado School of Mines, Golden, CO, May.

Clancey, W. J. 2004a. Automating Capcom: Pragmatic Operations and Technology Research for Human Exploration of Mars. In C. Cockell (ed.) Martian Expedition Planning, Vol. 107, AAS Science and Technology Series, pp. 411-430.

Clancey, W. J. 2004b. Roles for agent assistants in field science: Understanding personal projects and collaboration. IEEE Transactions on Systems, Man and Cybernetics, Part C: Applications and Reviews, Special Issue on Human-Robot Interaction, May 2004, Volume 34, Number 2, pp. 125-137.

Clancey, W. J. (in preparation). Observation in Natural Settings. To appear in R. Hoffman (ed.) Cambridge Handbook on Expertise and Expert Performance, Part III: "Methods for Studying the Structure of Expertise.” New York: Cambridge University Press.

Clancey, W.J, Sierhuis, M., Alena, R., Crawford, S., Dowding, J., Graham, J., Kaskiris, C., Tyree, K. S., and vanHoof, R. 2004a. Mobile Agents: A Distributed Voice-Commanded Sensory and Robotic System for Surface EVA Assistance. In R. B. Malla and A. Maji (eds), Engineering, Construction, and Operations in Challenging Environments: Earth and Space 2004, Houston: ASCE. pp. 85-92.

Clancey, W.J, Sierhuis, M., Alena, R., Crawford, S., Dowding, J., Graham, J., Kaskiris, C., Tyree, K. S., and vanHoof, R. 2004b. The Mobile Agents Integrated Field Test: The Mars Desert Research Station April 2003. Proc. FLAIRS-2004. CD-ROM.

Clancey, W.J, Sierhuis, M., Alena, R., Dowding, J., Garry, B., Graham, J., Rupert, S., Semple, A., Tyree, K. S., and vanHoof, R. 2004c. The Mobile Agents 2004 Field Test at MDRS: Fitting Robot Capabilities to Human Activities. Mars Society Annual Meeting, abstract, August.

Cohen, M. M. 1985. Human factors in space station architecture I: Space station program implications for human factors research. NASA Technical Memorandum No. 86702. 
Clancey: Participant Observation of a Mars Surface Habitat Mission Simulation

Cohen, M. M. 1997. Human engineering for SOFIA. Presented at the American Institute of Aeronautics and Astronautics World Aviation Congress, Anaheim, October. SAE International Publications No. 975632.

Compton, W. D. and Benson, C. D. 1983. Living and Working in Space: A History of Skylab. NASA History Series. Special Publication No. SP-4208. URL: http://history.nasa.gov/SP-4208/sp4208.htm

Connolly, J. F. 1999. Mars design example. In J. Larson and L. K. Pranke (eds.) Human Spaceflight: Mission Analysis and Design, New York: McGraw-Hill, pp. 981-1002.

Connors, M.M., Harrison, A. A., and Akins, F. R. 1985. Living Aloft: Human Requirements for Extended Spaceflight. NASA SP-483. URL: http://www.jamesoberg.com/links/links.html.

Ehn, P. 1988. Work-Oriented Design of Computer Artifacts, Stockholm: Arbeslivscentrum.

Greenbaum, J., and Kyng, M. (eds.) 1991. Design at Work: Cooperative Design of Computer Systems. Hillsdale, NJ: Lawrence Erlbaum Associates.

Floyd, C. 1987. Outline of a paradigm shift in software engineering, in Bjerknes, et al., (eds.) Computers and Democracy-A Scandinavian Challenge, p. 197.

Harrison, A., Clearwater, Y., and McKay, C. 1991. From Antarctica to Outer Space: Life in Isolation and Confinement. New York: Springer-Verlag.

Hoffman, S. J., and Kaplan, D. I. (eds.) 1997. Human Exploration of Mars: The Reference Mission of the NASA Mars Exploration Study Team. NASA Special Publication 6107. Lyndon B. Johnson Space Center, Houston, Texas. (Addendum, Reference Mission Version 3.0, June 1998, EX13-98-036.)

Johnson, A. and Sackett, R. 1998. Direct systematic observation of behavior. In H. R. Bernard, (ed.) Handbook of Methods in Cultural Anthropology, pp. 301-331. Walnut Creek: Altamira.

Jordan, B. 1994. Ethnographic workplace studies and computer supported cooperative work. Proceedings of the Interdisciplinary Workshop on Informatics and Psychology, Schärding, Austria, June 1-3, 1993. Amsterdam: North Holland.

Kanas, N. 2002. Psychosocial and psychiatric issues of space, Journal of Gravitational Physiology, 9(1) 307-310.

Larson, W. J. and Balogh, W. 1999. Designing human space missions. In J. Larson and L. K. Pranke (eds.) Human Spaceflight: Mission Analysis and Design, New York: McGraw-Hill, pp. 17-52.

Larson, W. J. and Pranke, L. K. (eds.) 1999. Human Spaceflight: Mission Analysis and Design. New York: McGraw-Hill.

Leninger, J. M. 2000. Off the Planet: Surviving five perilous months aboard the space station Mir. New York: McGraw-Hill.

Luff, P., Hindmarsh, J., and Heath, C. (eds.) 2000. Workplace studies: recovering work practice and informing system design. Cambridge: Cambridge University Press.

Lunar-Mars Life Support Test Project 1997. http://advlifesupport.jsc.nasa.gov/lmlstp.html.

Malone, T. 2004. The Future of Work. Boston: Harvard Business School Press.

Perrow, C. 1999. Normal accidents: Living with high-risk technologies. Princeton: Princeton University Press.

Persaud, R. 2004. A Systematic Approach to Investigations at Mars Analog Research Stations. In C. Cockell (ed.) Martian Expedition Planning, Vol. 107, AAS Science and Technology Series, pp. 103122. 
Senge, P. M. 1990. The Fifth Discipline: The Art \& Practice of the Learning Organization. New York: Doubleday.

Sierhuis, M. 2001. Modeling and simulating work practice. Ph.D. thesis, Social Science and Informatics (SWI), University of Amsterdam, SIKS Dissertation Series No. 2001-10, Amsterdam, The Netherlands, ISBN 90-6464-849-2.

Sklar, S. 2004. A field methodology approach for collaborative crew and RST data analysis. Presented at the Mars Society Annual Meeting. Chicago, IL.

Spradley, J. P. 1980. Participant observation. Fort Worth: Harcourt Brace College Publishers.

Stuster, J. 1996. Bold endeavors: Lessons from polar and space exploration. Annapolis: Naval Institute Press.

Todd, B. and Reagan, M. 2004. The NEEMO Project: A report on how NASA utilizes the "Aquarius" undersea habitat as an analog for long-duration space flight. In R. B. Malla and A. Maji (eds), Engineering, Construction, and Operations in Challenging Environments: Earth and Space 2004, Houston: ASCE. pp. 751-758.

Vicente, K. J. 1999. Cognitive Work Analysis: Toward Safe, Productive, and Healthy Computer-Based Work. Mahwah, NJ: LEA.

Woolford, B., Bond, R. L., 1999. Human factors of crewed spaceflight. In W. J. Larson and L. K. Pranke (eds.) Human Spaceflight: Mission Analysis and Design, New York: McGraw-Hill, pp. 133-153.

Zuboff, S. 1988. In the Age of the Smart Machine: The future of work and power. New York: Basic Books, Inc.

Zubrin, R. (with Richard Wagner). 1996. The Case for Mars: The Plan to settle the red planet and why we must. NY: The Free Press.

Zubrin, R. 2003. Mars on Earth: The adventures of space pioneers in the High Arctic. New York: Jeremy P. Tarcher.

Zubrin R. and Crossman, F. 2002. On to Mars: Colonizing a new world. Burlington, Ontario, Canada: Apogee Books. CD-ROM. 